\title{
Essential Oil from Hedyotis chrysotricha: Chemical Composition, Cytotoxic, Antibacterial Properties and Synergistic Effects with Streptomycin
}

\author{
Xinyu Li $\odot$, Weijia Zhang $\odot$, Yu Qin $\odot$ and Xiang Xing \\ Marine College, Shandong University, Weihai 264209, China \\ (Received August 12, 2021; Revised September 13, 2021; Accepted September 15, 2021)
}

\begin{abstract}
Hedyotis chrysotricha (Palib.) Merr. is a traditional Chinese herb that has been used to treat multiple ailments. In this study, we extracted and characterized the essential oil of $H$. chrysotricha for the first time and assessed its in vitro cytotoxic, antibacterial activities and the synergistic interaction with Streptomycin. Chemical constituents were determined using GC-FID/MS, which showed 37 components constituted $94.7 \%$ of the total oil; borneol (32.7\%), linalool (7.5\%), isobornyl formate (5.4\%) and $\alpha$-terpineol (4.8\%) were the dominant components. The essential oil of $H$. chrysotricha inhibited strongly the growth of Gram-positive bacteria and possessed a significant cytotoxic activity towards LO2, HepG2 and MCF-7 cells. Besides, the checkerboard assay revealed that the $H$. chrysotricha essential oil exhibited synergistic potential with Streptomycin. Based on these findings, it can be concluded that the $H$. chrysotricha essential oil exhibits interesting bioactivities, and could be used as a source of natural antibacterial and anti-tumor compounds.
\end{abstract}

Keywords: Hedyotis chrysotricha (Palib.) Merr; essential oil; antibacterial activity; cytotoxic activity; synergistic effects. (C) 2022 ACG Publications. All rights reserved.

\section{Plant Source}

The aerial parts of Hedyotis chrysotricha (Palib.) Merr. were collected in Zhejiang Province, China, in August 2020. The plants were identified and authenticated by Prof. Hong Zhao. The voucher specimen (NO.020015) has been deposited at the Laboratory of Botany, Shandong University, China.

\section{Previous Studies}

Hedyotis chrysotricha (Palib.) Merr. [synonym: Oldenlandia chrysotricha (Palib.) Chun.], is a perennial herb belonging to the family Rubiaceae with a wide distribution throughout Southern China [1]. As a plant ingredient for Chinese traditional medicine, H. chrysotricha is extensively utilized for the treatment of rheumatic arthritis, acute nephritis, hepatitis and cancer [2]. Pharmacological studies have demonstrated that extracts of the whole plant of $H$. chrysotricha possessed inhibitory activities against the growth of SK-HEP-1 human hepatocellular carcinoma cells and HL-60 human leukemia cells $[3,4]$. Several alkaloids and iridoid glucosides had been reported from H. chrysotricha in the

\footnotetext{
*Corresponding author: E-Mail: xingxiang@email.sdu.edu.cn; Phone +86-631-5688303. 
Xing et al., Rec. Nat. Prod. (2022) 16:4 376-381

previous phytochemical studies [2-4]. Additionally, a trace alkaloid chrysotricine was isolated from the alcoholic extracts of $H$. chrysotricha which exhibits an in vitro cytotoxic activity against HL-60 cells [4]. However, a search of the literature revealed no previous study has investigated the essential oil of $H$. chrysotricha. Accordingly, the present study was undertaken to describe the composition of the essential oil of $H$. chrysotricha (HC-EO) and to evaluate its biological activities.

\section{Present Study}

The aerial parts of $H$. chrysotricha were hydrodistilled to give an essential oil in a yield of 0.15 $\pm 0.03 \%$ (w/w), calculated on a dry weight basis. The compounds are listed in Table 1 according to the elution on an HP-5 MS capillary column.

Table 1. Percentage compositions identified in the essential oil of aerial parts of H. chrysotricha

\begin{tabular}{|c|c|c|c|c|}
\hline Compounds $^{\text {a }}$ & $\mathbf{R I}^{\mathbf{b}}$ & $R I_{\text {lit }}{ }^{c}$ & RI range $^{d}$ & $\%$ \\
\hline Cumene & 926 & $924^{\mathrm{e}}$ & & 1.2 \\
\hline Lavender lactone & 1038 & $1034^{\mathrm{e}}$ & & 2.4 \\
\hline cis-Linalool Oxide & 1070 & $1067^{\mathrm{e}}$ & $1061-1090$ & 2.5 \\
\hline trans-Linalool oxide & 1086 & $1084^{\mathrm{e}}$ & 1070-1097 & 2.2 \\
\hline Linalool & 1099 & $1095^{\mathrm{e}}$ & $1088-1109$ & 7.5 \\
\hline trans-Sabinene hydrate & 1110 & $1107^{\mathrm{f}}$ & $1084-1115$ & 1.5 \\
\hline Nopinone & 1139 & $1135^{\mathrm{e}}$ & $1120-1145$ & 1.8 \\
\hline Camphor & 1145 & $1141^{\mathrm{e}}$ & $1127-1155$ & 3.7 \\
\hline Borneol & 1169 & $1165^{\mathrm{e}}$ & $1152-1177$ & 32.7 \\
\hline$\alpha$-Terpineol & 1192 & $1186^{\mathrm{e}}$ & $1178-1203$ & 4.8 \\
\hline 2-Methylisoborneol & 1197 & $1197^{\mathrm{g}}$ & & 1.7 \\
\hline Isobornyl formate & 1232 & $1235^{\mathrm{e}}$ & & 5.4 \\
\hline Bornyl acetate & 1288 & $1289^{\mathrm{e}}$ & $1264-1297$ & 1.9 \\
\hline$(E, E)$-2,4-Decadienal & 1317 & $1315^{\mathrm{e}}$ & $1305-1334$ & 0.3 \\
\hline Dehydro-ar-ionene & 1359 & $1354^{\mathrm{g}}$ & & 0.2 \\
\hline 1-Tetradecene & 1389 & $1388^{\mathrm{e}}$ & & 0.5 \\
\hline Hexahydropseudoionone & 1403 & $1408^{\mathrm{g}}$ & & 0.2 \\
\hline (E)- $\alpha$-Ionone & 1430 & $1428^{\mathrm{e}}$ & $1403-1435$ & 0.5 \\
\hline$\beta$-Barbatene & 1452 & $1452^{\mathrm{f}}$ & & 0.5 \\
\hline Dehydro- $\beta$-ionone & 1486 & $1485^{\mathrm{g}}$ & & 0.3 \\
\hline$(E)-\beta$-Ionone & 1489 & $1487^{\mathrm{e}}$ & $1470-1498$ & 1.3 \\
\hline Caryophyllene oxide & 1585 & $1582^{\mathrm{e}}$ & $1563-1595$ & 0.6 \\
\hline Tetradecanal & 1609 & $1611^{\mathrm{e}}$ & $1605-1623$ & 0.6 \\
\hline Junenol & 1618 & $1618^{\mathrm{e}}$ & & 0.3 \\
\hline (Z)-6,7-Dihydrofarnesol & 1674 & $1673^{\mathrm{f}}$ & & 1.0 \\
\hline 2-Pentadecanone & 1694 & $1697^{\mathrm{e}}$ & $1685-1716$ & 0.9 \\
\hline Pentadecanal & 1711 & $1715^{\mathrm{f}}$ & $1703-1728$ & 2.9 \\
\hline Octadecene & 1787 & $1789^{\mathrm{e}}$ & & 0.6 \\
\hline Neophytadiene & 1838 & $1841^{\mathrm{f}}$ & & 2.4 \\
\hline Hexahydrofarnesyl acetone & 1844 & $1847^{\mathrm{f}}$ & & 3.9 \\
\hline (Z)-9-Hexadecen-1-ol & 1877 & $1863^{\mathrm{g}}$ & & 0.8 \\
\hline Methyl hexadecanoate & 1921 & $1921^{\mathrm{e}}$ & 1910-1931 & 1.5 \\
\hline Isophytol & 1945 & $1946^{\mathrm{e}}$ & 1939-1951 & 1.5 \\
\hline Hexadecanoic acid & 1955 & $1959^{\mathrm{e}}$ & 1939-1996 & 0.3 \\
\hline Ethyl hexadecanoate & 1988 & $1992^{\mathrm{e}}$ & $1975-2000$ & 0.3 \\
\hline Eicosene & 1990 & $1987^{\mathrm{e}}$ & & 0.2 \\
\hline Oleic acid & 2141 & $2141^{\mathrm{e}}$ & $2102-2161$ & 3.8 \\
\hline Total identified & & & & 94.7 \\
\hline
\end{tabular}

\footnotetext{
${ }^{a}$ Compounds are listed in order of their elution on the HP-5MS column; ${ }^{b}$ RI: Retention index on the HP-5MS column relative
} to $\mathrm{C}_{7}-\mathrm{C}_{30}$ n-alkanes; ${ }^{\mathbf{c}} \mathbf{R} \mathbf{I}_{\text {lit }}$ : Retention indices data from the literature e) [16], f) [17] and g) [18]; ${ }^{\mathbf{d}} \mathbf{R I}$ range: range of Kováts 
Biological activities of essential oil from Hedyotis chrysotricha

retention indices (90\% confidence) reported by Babushok et al. (2011) [19].

Using GC-FID and GC-MS, a total of 37 compounds, representing $94.7 \%$ of the total essential oil content were identified (The experiments' details were provided in Supporting Information).

The major constituents of the HC-EO were borneol (32.7\%), linalool (7.5\%), isobornyl formate (5.4\%), $\alpha$-terpineol (4.8\%), hexahydrofarnesyl acetone (3.9\%) and oleic acid (3.8\%). Borneol is a naturally occurring bicyclic monoterpene, widely used in Chinese folk medicine for the treatment of sore throat, treating burns, wound healing, and skin infections [5]. It was also reported to exhibit a variety of pharmacological activities, such as antioxidant, anti-inflammation [6], antinociceptive [7] and antiepileptogenic activities [8]. Linalool is a monoterpene alcohol with various pharmacological activities, including antimicrobial [9], neuroprotective [10], antinociceptive [11], anti-inflammatory [12], antiproliferative and anticancer effects [13]. Another monoterpene alcohol, $\alpha$-terpineol, has also been demonstrated to possess a broad spectrum of pharmacological properties, such as anticonvulsant, antidiarrheal, antimicrobial, gastroprotective [14], anti-inflammatory [15].

Antibacterial Activity of the Essential Oil: The antibacterial activity of the essential oil was tested by micro-broth dilution method against four bacterial strains, belonging to both Gram-positive and Gramnegative bacteria - namely Bacillus subtilis (ATCC 6633) and Staphylococcus aureus (ATCC 6538) represent Gram-positive; and Escherichia coli (ATCC 25922) and Pseudomonas aeruginosa (ATCC 27853) represent Gram-negative bacteria [20]. The minimal inhibitory concentrations (MICs) and Minimal bactericidal concentration (MBCs) of the oil were listed in Table 2. Chloramphenicol was used as the positive control. The results revealed that the essential oil of $H$. chrysotricha showed significant antibacterial activity on Gram-positive bacteria $S$. aureus and B. subtilis with MICs of $0.039 \mathrm{mg} / \mathrm{mL}$ and $0.078 \mathrm{mg} / \mathrm{mL}$, and a moderate activity on Gram-negative bacteria $E$. coli and $P$. aeruginosa $(\mathrm{MICs}=$ $0.625 \mathrm{mg} / \mathrm{mL}$ ). Accordingly, it could be observed that Gram-positive bacteria were more sensitive to the essential oil of $H$. chrysotricha than Gram-negative bacteria.

Table 2. Antibacterial activity of $H$. chrysotricha essential oil

\begin{tabular}{lcccc}
\hline Bacteria & \multicolumn{2}{c}{ MIC $^{\mathbf{1}}$} & \multicolumn{2}{c}{ MBC $^{2}$} \\
& EO $(\mathbf{m g} / \mathbf{m L})$ & $\begin{array}{c}\mathbf{C h} \\
(\mathbf{m g} / \mathbf{m L})\end{array}$ & $\mathbf{E O}(\mathbf{m g} / \mathbf{m L})$ & $\begin{array}{c}\text { Ch } \\
(\mathbf{m g} / \mathbf{m L})\end{array}$ \\
\hline Gram-positive & & & & \\
Bacillus subtilis ATCC 6633 & 0.078 & 0.016 & 0.078 & 0.031 \\
Staphylococcus aureus ATCC 6538 & 0.039 & 0.008 & 0.078 & 0.031 \\
Gram-negative & & & & \\
Escherichia coli ATCC 25922 & 0.625 & 0.031 & 0.625 & 0.125 \\
Pseudomonas aeruginosa ATCC 27853 & 0.625 & 0.062 & 1.250 & 0.125 \\
\hline
\end{tabular}

${ }^{1}$ Minimal inhibitory concentration; ${ }^{2}$ Minimal bactericidal concentration; Ch, chloramphenicol.

Synergistic Effects Screening: The checkerboard assay was conducted to estimate the synergistic interactions between the essential oil and antimicrobial agent Streptomycin [20]. The study showed that HC-EO presented a marked synergistic effect in combination with Streptomycin against reference strains (the FICI values ranged from 0.19 to 0.38 ). The detailed results are summarized in Table 3. 
Table 3. The antibacterial activity of essential oils in combination with Streptomycin

\begin{tabular}{ccccc}
\hline Bacteria & & $\mathrm{MIC}_{\mathrm{a}}(\mu \mathrm{g} / \mathrm{mL})$ & $\mathrm{MIC}_{\mathrm{c}}(\mu \mathrm{g} / \mathrm{mL})$ & FICI \\
\hline Bacillus subtilis & $\mathrm{EO}$ & 78.13 & 19.53 & $0.31(\mathrm{~S})$ \\
ATCC 6633 & $\mathrm{SM}$ & 2.50 & 0.16 & $0.31(\mathrm{~S})$ \\
\hline Staphylococcus aureus & $\mathrm{EO}$ & 39.06 & 9.77 & 0.31 \\
ATCC 6538 & $\mathrm{SM}$ & 5.00 & 78.13 & \\
\hline Escherichia coli & $\mathrm{EO}$ & 625.00 & 1.25 & $0.19(\mathrm{~S})$ \\
ATCC 25922 & $\mathrm{SM}$ & 5.00 & 39.06 & \\
\hline Pseudomonas aeruginosa & $\mathrm{EO}$ & 625.00 & 0.63 & \\
\hline ATCC 27853 & $\mathrm{SM}$ & 5.00 & & \\
\hline
\end{tabular}

$\mathrm{MIC}_{\mathrm{a}}$ : $\mathrm{MIC}$ of an individual sample; $\mathrm{MIC}_{\mathrm{c}}$ : $\mathrm{MIC}$ at the most effective combination; FICI: fractional inhibitory concentration index; SM: Streptomycin; S, synergy (FICI $\leq 0.5)$.

In vitro Cytotoxic Activity Evaluation: The potential cytotoxic activity of $H$. chrysotricha essential oil was carried out by MTT assay in vitro and measured in four human cancer cell lines, namely HepG2 liver cancer cells, MCF-7 breast cancer cells, A-549 lung cancer cells, HCT-116 colon cancer cells, and a normal human hepatocyte cell line LO2 [21]. Doxorubicin was used as a reference drug. All cells were exposed to increasing concentrations of HC-EO or Doxorubicin for $24 \mathrm{~h}, 48 \mathrm{~h}$ and $72 \mathrm{~h}$, respectively. As shown in Table 4, the essential oil of $H$. chrysotricha revealed strong cytotoxic activities towards LO2, HepG2, and MCF-7 with $\mathrm{IC}_{50}$ values range from $12.55 \pm 0.76$ to $19.52 \pm 0.49 \mu \mathrm{g} / \mathrm{mL}$ for $72 \mathrm{~h}$. Moderate cytotoxic effects towards HCT-116 and A-549 cells with $\mathrm{IC}_{50}$ values of $20.87 \pm 0.41$ and 42.45 $\pm 1.58 \mu \mathrm{g} / \mathrm{mL}$ for $72 \mathrm{~h}$ were also observed.

Table 4. Cytotoxicity $\left(\mathrm{IC}_{50} \mu \mathrm{g} / \mathrm{mL}\right)$ of the essential oil from H. chrysotricha

\begin{tabular}{llrrr}
\hline & Sample & \multicolumn{1}{c}{$24 \mathrm{~h}$} & \multicolumn{1}{c}{$48 \mathrm{~h}$} & \multicolumn{1}{c}{$72 \mathrm{~h}$} \\
\hline \multirow{2}{*}{ HepG2 } & EO & $42.56 \pm 3.39$ & $30.76 \pm 12.23$ & $14.43 \pm 2.74$ \\
& Doxorubicin & $1.46 \pm 0.08$ & $1.09 \pm 0.08$ & $0.43 \pm 0.07$ \\
\multirow{2}{*}{ MCF-7 } & EO & $34.37 \pm 3.48$ & $24.43 \pm 4.16$ & $19.52 \pm 0.49$ \\
& Doxorubicin & $1.56 \pm 0.03$ & $0.79 \pm 0.02$ & $0.39 \pm 0.06$ \\
\multirow{2}{*}{ LO2 } & EO & $24.89 \pm 3.94$ & $16.19 \pm 5.11$ & $12.55 \pm 0.76$ \\
& Doxorubicin & $1.80 \pm 0.29$ & $0.46 \pm 0.02$ & $0.55 \pm 0.12$ \\
\multirow{2}{*}{ A-549 } & EO & $62.01 \pm 4.08$ & $48.11 \pm 2.92$ & $42.45 \pm 1.58$ \\
& Doxorubicin & $1.04 \pm 0.07$ & $0.85 \pm 0.05$ & $0.33 \pm 0.01$ \\
\multirow{2}{*}{ HCT-116 } & EO & $46.77 \pm 3.71$ & $32.08 \pm 5.13$ & $20.87 \pm 0.41$ \\
& Doxorubicin & $1.33 \pm 0.15$ & $0.57 \pm 0.02$ & $0.48 \pm 0.06$ \\
\hline
\end{tabular}

The bioactivities of essential oils could be attributed to their constituents. Some predominance components of $H$. chrysotricha essential oil have been reported for their antibacterial and cytotoxic activities, such as borneol [22], linalool [9,13], $\alpha$-terpineol [9, 23], hexahydrofarnesyl acetone [24] and oleic acid [25]. Besides, the possible synergistic effects among all of the components in essential oil may be also responsible for these activities.

Overall, the present study has, for the first time, identified the composition of $H$. chrysotricha essential oil, and demonstrated the HC-EO exhibit a potential cytotoxic activity towards LO2, HepG2 and MCF-7 cells, and a significant antibacterial activity against gram-positive bacteria strains, as well as a remarkable synergistic interaction with Streptomycin. Accordingly, the essential oil of $H$. chrysotricha could be used as a source of natural antibacterial and anti-tumor compounds. However, further in vivo experimentation is required to provide more evidence for being used as a potential treatment of anti-tumor and control of pathogenic bacteria. 
Biological activities of essential oil from Hedyotis chrysotricha

\section{Supporting Information}

Supporting Information accompanies this paper on http://www.acgpubs.org/journal/recordsof-natural-products

\section{ORCID}

Xinyu Li: 0000-0003-2050-7397

Weijia Zhang: 0000-0001-9560-3549

Yu Qin: 0000-0003-1148-3362

Xiang Xing: 0000-0003-0951-5708

\section{References}

[1] X. R. Luo (1999). Flora of China. Science Press, Beijing. 71: pp. 38.

[2] J. N. Peng, X. Z. Feng and X. T. Liang (1999). Two new iridoids from Hedyotis chrysotricha, J. Nat. Prod. 62, 611-612.

[3] M. Ye, J. J. Su, S. T. Liu, L. Cao, J. Xiong, Y. Zhao, H. Fan, G. X. Yang, G. Xia and J. F. Hu (2013). (24 S)-Ergostane-3 $\beta, 5 \alpha, 6 \beta$-triol from Hedyotis chrysotricha with inhibitory activity on migration of SKHEP-1 human hepatocarcinoma cells, Nat. Prod. Res. 27, 1136-1140.

[4] J. N. Peng, X. Z. Feng, Q. T. Zheng and X. T. Liang (1997). A $\beta$-carboline alkaloid from Hedyotis chrysotricha, Phytochemistry 46, 1119-1121.

[5] J. R. Almeida, G. R. Souza, J. C. Silva, S. R. Saraiva, R. G. Júnior, Jde. S. Quintans, Rde. S. Barreto, L. R. Bonjardim, S. C. Cavalcanti and L. J. QuintansJr. (2013). Borneol, a bicyclic monoterpene alcohol, reduces nociceptive behavior and inflammatory response in mice, Sci. World J. 2013, 808460.

[6] R. Liu, L. Zhang, X. Lan, L. Li, T. T. Zhang, J. H. Sun, and G. H. Du (2011). Protection by borneol on cortical neurons against oxygen-glucose deprivation/reperfusion: involvement of anti-oxidation and antiinflammation through nuclear transcription factor кappaB signaling pathway, Neuroscience 176, 408-419.

[7] M. Takaishi, K. Uchida, F. Fujita and M. Tominaga (2014). Inhibitory effects of monoterpenes on human TRPA1 and the structural basis of their activity, J. Physiol. Sci. 64, 47-57.

[8] R. Tambe, P. Jain, S. Patil, P. Ghumatkar and S. Sathaye (2016). Antiepileptogenic effects of borneol in pentylenetetrazole-induced kindling in mice, N-S Arch Pharmacol. 389, 467-475.

[9] S. N. Park, Y. K. Lim, M. O. Freire, E. Cho, D. Jin and J. K. Kook (2012). Antimicrobial effect of linalool and $\alpha$-terpineol against periodontopathic and cariogenic bacteria, Anaerobe 18, 369-372.

[10] H. Park, G. H. Seol, S. Ryu and I. Y. Choi (2016). Neuroprotective effects of (-)-linalool against oxygenglucose deprivation-induced neuronal injury, Arch. Pharm. Res. 39, 555-564.

[11] I. Pereira, P. Severino, A. C. Santos, A. M. Silva and E. B. Souto (2018). Linalool bioactive properties and potential applicability in drug delivery systems, Colloid. Surface. B. 171, 566-578.

[12] Y. Li, O. Lv, F. Zhou, Q. Li, Z. Wu and Y. Zheng (2015). Linalool inhibits LPS-induced inflammation in BV2 microglia cells by activating Nrf2, Neurochem. Res. 40, 1520-1525.

[13] K. Iwasaki, Y. W. Zheng, S. Murata, H. Ito, K. Nakayama, T. Kurokawa, N. Sano, T. Nowatari, M. O. Villareal, Y. N. Nagano, H. Isoda, H. Matsui and N. Ohkohchi (2016). Anticancer effect of linalool via cancer-specific hydroxyl radical generation in human colon cancer, Word J. Gastroenterol. 22, 9765-9774.

[14] C. Khaleel, N. Tabanca and G. Buchbauer (2018). $\alpha$-Terpineol, a natural monoterpene: A review of its biological properties, Open Chem. 16, 349-361.

[15] M. N. M. Nogueira, S. G. Aquino, C. Rossa Junior and D. M. P. Spolidorio (2014). Terpinen-4-ol and alpha-terpineol (tea tree oil components) inhibit the production of IL-1 $\beta$, IL-6 and IL-10 on human macrophages, Inflamm. Res. 63, 769-778.

[16] R. P. Adams (2017). Identification of essential oil components by gas chromatography/mass spectrometry. 5th Ed. Texensis Publishing Gruver, TX USA.

[17] N. R. Andriamaharavo (2014). Retention Data NIST Mass Spectrometry Data Center, NIST Mass Spectrometry Data Center. 
Xing et al., Rec. Nat. Prod. (2022) 16:4 376-381

[18] P. J. Linstrom and W.G. Mallard (2014). NIST Chemistry WebBook, NIST Standard Reference Database Number 69. (http://webbook.nist.gov).

[19] V. I. Babushok, P. J. Linstrom and I. G. Zenkevich (2011). Retention indices for frequently reported compounds of plant essential oils, J. Phys. Chem. Ref. Data. 40(4), 1-47.

[20] H. Rao, P. Lai and Y. Gao (2017). Chemical composition, antibacterial activity, and synergistic effects with conventional antibiotics and nitric oxide production inhibitory activity of essential oil from Geophila repens (L.) I.M. Johnst, Molecules 22, 1561-1573.

[21] X. D. Su, Yang Gao, Y. X. Xiang, P. X. Lai and X. Xing (2019). Chemical composition and biological activities of the essential oil from Aristolochia fordiana Hemsl, Rec. Nat. Prod. 13, 346-354.

[22] N. Tabanca, N. Kırımer, B. Demirci, F. Demirci and K. H. C. Başer (2001). Composition and antimicrobial activity of the essential oils of Micromeria cristata subsp. phrygia and the enantiomeric distribution of borneol, J. Agric. Food Chem. 49, 4300-4303.

[23] R. Noor and I. Astuti (2014). Cytotoxicity of $\alpha$-terpineol in HeLa cell line and its effects to apoptosis and cell cycle, J. Med. Sci. 46, 1-9.

[24] N. Filipowicz, M. Kamiński, J. Kurlenda, M. Asztemborska and J. R. Ochocka (2003). Antibacterial and antifungal activity of juniper berry oil and its selected components, Phytother. Res. 17, 227-231.

[25] D. P. Speert, L. W. Wannamaker, E. D. Gray and C. C. Clawson (1979). Bactericidal effect of oleic acid on group A streptococci: mechanism of action, Infect. Immun. 26, 1202-1210.

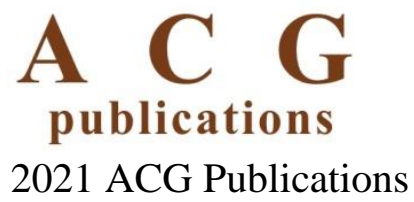

